\title{
Application of deflection bowl parameters for assessing different structures of road pavement
}

\author{
Bagus Hario Setiadji ${ }^{1, *}$ \\ ${ }^{1}$ Department of Civil Engineering, Diponegoro University, Semarang, Indonesia
}

\begin{abstract}
To date, non-destruction testing (NDT) method is the most popular method to assess the condition of road pavement. Among all evaluation procedures of the NDT method, load-deflection backcalculation analysis is one that is developed widely to understand the structural behavior of road pavement. On one side, the use of this analysis is greatly beneficial for presenting the layer characteristic accurately. However, the analysis requires specialist expertise. To overcome this, deflection bowl parameter application could become one alternative. The parameters are very easy to use; however, the intention of the parameters so far is only as an indication of the condition of the structural layer of the road pavement. Therefore, the parameters have to be used with careful consideration. In this study, the parameters were evaluated to determine the optimal usage of the parameters against different structures of road pavements. The results showed that a simplification of the number of parameters and a reformulation of the parameters were required by taking into account the ease of use in practice, the accuracy of subgrade modulus determination and the possibility to evaluate pavement structures with a layer number less than four.
\end{abstract}

\section{Introduction}

At present, highway agencies have been encouraged to use more non-destructive testing (NDT) methods to evaluate the structural conditions of pavement. The main reason for this is because the NDT method leaves the pavement structure intact. So far, there are two methods of NDT in evaluating the pavement structure: the seismic method (known as spectral analysis of surface waves/SASW method) and deflection method (and then using a back-calculation program to determine layer's elastic modulus). The latter is now more popular; however, it requires specialists with in-depth knowledge about materials and its behavior, and also information about layer thicknesses [1] to enable the calculation of the modulus value to be accurate. Both of the above requirements often become obstacles preventing wider acceptance of the NDT method.

In 1987, Horak introduced the use of deflection bowl parameters as an alternative evaluation of the structures of the road pavement [1,2]. Deflection bowl parameters are defined as parameters that make use of the deflection curve produced by the fallingdeflectometer (FWD) device as guidance to evaluate individual layer strength and determine the location along the road pavement that needs rehabilitation. The use of these parameters is quite simple and does not require the determination of the thickness of the

\footnotetext{
*Corresponding author: bhsetiadji@ft.undip.ac.id
} 
layer as one of its requirements. When compared with the back-calculation method, the use of this parameter will not produce detailed results, but only an indication of the structural conditions of a pavement. If the elastic modulus of the layers needs to be obtained, the agency then has to use back-calculation applications. However, for field use, deflection bowl parameters are sufficient as an evaluation of structural damage from pavement structures.

The deflection bowl parameter at the time of its development is based on a 4-layer pavement structure (surface, base, subbase, and subgrade), whereas at present the flexible pavement structure may have less or more than four layers. In addition, with respect to the application of deflection bowl parameters on multi-layer pavement structures, it is questionable whether the use of sensors within the parameters is completely thickness-free. To answer the above questions, this research is proposed to ensure that the parameters can be used in all conditions in practice.

\section{Deflection bowl parameters}

In the late 1980s, the FWD device was known as a tool to measure the response of the pavement structure (deflection) due to impulse load. This device has an ability to measure deflections simultaneously so that a deflection curve or deflection bowl can be obtained. The existence of the deflection bowl then led to the development of several deflection bowl parameters in which each parameter defines a certain structural condition of a pavement layer. Horak and Emery [2] suggested five deflection bowl parameters that have good correlations with the corresponding pavement structural conditions. Among the five parameters, four of them have a direct association with the four-layer pavement structure: maximum deflection $\left(D_{0}\right)$, base layer index $(B L I)$, middle layer index $(M L I)$ and lower layer index $(L L I)$. The formulas of the last three indices were shown below.

$$
\begin{gathered}
B L I=D_{0}-D_{300} \\
M L I=D_{300}-D_{600} \\
L L I=D_{600}-D_{900}
\end{gathered}
$$

in which: $D_{0}, D_{300}, D_{600}, D_{900}$ are the deflection at sensor offset $0,300,600$ and $900 \mathrm{~mm}$, respectively from the load.

The determination of the parameters does not require the measurement of layer thickness. In practice, all parameters can be used as an indication of the layer structural condition. $D_{0}$ generally indicates all structural layers with $70 \%$ contributed by subgrade, while $B L I, M L I$, and $L L I$ represent the indication of the condition of the base, subbase, and subgrade, respectively.

In addition, the parameters can be widely used to categorize the pavement layer according to a certain criterion, as seen in Tables 1 and 2. Table 1 shows the use of the

\begin{tabular}{|c|c|c|c|c|}
\hline \multicolumn{4}{|c|}{ Deflection Bowl Parameters (mm) } & \multirow{2}{*}{$\begin{array}{l}\text { Behaviour } \\
\text { State }\end{array}$} \\
\hline$D_{0}$ & $B L I=D_{0}-D_{300}$ & $M L I=D_{300}-D_{600}$ & $L L I=D_{600}-D_{900}$ & \\
\hline$<0.3$ & $<0.08$ & $<0.05$ & $<0.04$ & Very Stiff \\
\hline $0.3-0.5$ & $0.08-0.25$ & $0.05-0.15$ & $0.04-0.08$ & Stiff \\
\hline $0.5-0.75$ & $0.25-0.50$ & $0.15-0.20$ & $0.08-0.10$ & Flexible \\
\hline$>0.75$ & $>0.50$ & $>0.20$ & $>0.10$ & Very Flexible \\
\hline
\end{tabular}
parameters to classify the pavement layer based on the behavior state of the materials.

Table 1. Behaviour State for Flexible Pavement with Granular Base [1, 3] 
Table 2. Structural condition rating criteria for pavement structure with different base layer material $[1,3]$

\begin{tabular}{|c|c|c|c|c|c|}
\hline \multirow{3}{*}{$\begin{array}{c}\text { Type of } \\
\text { Base }\end{array}$} & \multicolumn{4}{|c|}{ Deflection Bowl Parameters (mm) } & \multirow{2}{*}{$\begin{array}{c}\text { Structural } \\
\text { condition } \\
\text { rating }\end{array}$} \\
\cline { 2 - 6 } & $\boldsymbol{D}_{\mathbf{0}}$ & $\begin{array}{c}\boldsymbol{B L I}=\boldsymbol{D}_{\mathbf{0}}- \\
\boldsymbol{D}_{\mathbf{3 0 0}}\end{array}$ & $\begin{array}{c}\boldsymbol{M L I}=\boldsymbol{D}_{\mathbf{3 0 0}}- \\
\boldsymbol{D}_{\mathbf{6 0 0}}\end{array}$ & $\begin{array}{c}\boldsymbol{L L I}=\boldsymbol{D}_{\mathbf{6 0 0}}- \\
\boldsymbol{D}_{\mathbf{9 0 0}}\end{array}$ & Sound \\
\hline \multirow{2}{*}{$\begin{array}{c}\text { Granular } \\
\text { base }\end{array}$} & $<0.50$ & $<0.20$ & $<0.10$ & $<0.05$ & Warning \\
\cline { 2 - 6 } & $0.50-0.75$ & $0.20-0.40$ & $0.10-0.20$ & $0.05-0.10$ & Severe \\
\cline { 2 - 6 } & $>0.75$ & $>0.40$ & $>0.20$ & $>0.10$ & Sound \\
\hline $\begin{array}{c}\text { Asphaltic } \\
\text { treated } \\
\text { base }\end{array}$ & $<0.40$ & $<0.20$ & $<0.10$ & $<0.05$ & Warning \\
\cline { 2 - 6 } & $0.40-0.60$ & $0.20-0.40$ & $0.10-0.15$ & $0.05-0.08$ & Severe \\
\hline
\end{tabular}

Remarks: the criteria may be adjusted to improve the sensitivity of evaluation

The use of Tables 1 and 2 should be taken into consideration with care since the development of both tables was empirically based, so that adjustment of the table might be required if a different material behavior is encountered.

\section{Methodology of study}

The methodology of the study consisted of two main parts:

1. Evaluation of existing deflection bowl parameters on different structures of road segments.

To do so, three types of pavement structures were used in this study, that is, pavement with 3, 4 and 5 layers. Six road segments (two per structure) extracted from the LongTerm Pavement Performance (LTPP) database [4] were selected. The details of the segments can be seen in Table 3.

Table 3. Details of road segments used in this study

\begin{tabular}{|c|c|c|}
\hline Road segment & No. of layers and total thickness *) & Layer details \\
\hline A & $3 / 7.5$ in. & $\begin{array}{l}\text { Subgrade (untreated) - infinite } \\
\text { Unbound granular base - } 3 \text { in. } \\
\text { Asphalt concrete layer - } 4.5 \mathrm{in} .\end{array}$ \\
\hline B & $3 / 11.9$ in. & $\begin{array}{l}\text { Subgrade (untreated) - } 204 \text { in. } \\
\text { Unbound granular base - } 9.6 \text { in. } \\
\text { Asphalt concrete layer - } 2.3 \text { in. }\end{array}$ \\
\hline $\mathrm{C}$ & $4 / 24.3$ in. & $\begin{array}{l}\text { Subgrade (untreated) - infinite } \\
\text { Unbound granular base }-16.2 \mathrm{in} . \\
\text { Asphalt concrete layer - } 6.6 \mathrm{in} . \\
\text { Asphalt concrete layer - } 1.5 \mathrm{in} .\end{array}$ \\
\hline $\mathrm{D}$ & $4 / 31.5$ in. & $\begin{array}{l}\text { Subgrade (untreated) - } 132 \mathrm{in.} \\
\text { Unbound granular base }-18.4 \mathrm{in} . \\
\text { Asphalt concrete layer - } 11.7 \mathrm{in.} \\
\text { Asphalt concrete layer - } 1.4 \mathrm{in} .\end{array}$ \\
\hline $\mathrm{E}$ & $5 / 16$ in. & $\begin{array}{l}\text { Subgrade (untreated) - infinite } \\
\text { Unbound granular subbase - } 4.7 \mathrm{in} . \\
\text { Unbound granular subbase - } 5.3 \mathrm{in} . \\
\text { Bound treated base }-5.0 \mathrm{in} . \\
\text { Asphalt concrete layer - } 1.0 \mathrm{in} .\end{array}$ \\
\hline $\mathrm{F}$ & $5 / 28.3$ in. & $\begin{array}{l}\text { Subgrade (untreated) - infinite } \\
\text { Unbound granular subbase - } 19.5 \text { in. } \\
\text { Bound treated base - } 4.6 \text { in. } \\
\text { Asphalt concrete layer - } 2.7 \text { in. } \\
\text { Asphalt concrete layer - } 1.5 \text { in. }\end{array}$ \\
\hline
\end{tabular}

Remarks: *) thickness without subgrade 
Two evaluations were conducted on:

(i) the possibility to use the parameters on different structures of the segments. Generally, the parameters were used for 4-layer pavement structures. In this study, the possibility to apply the parameters on 3-and 5-layer pavement structures was evaluated.

(ii) the possibility to use different sensors on the parameters. Horak and Emery [2] suggested the use of specific sensors for each parameter. The use of these sensors was preferable for 4-layer pavement structured and did not take into account the thickness of the layers. By using alternative structures in this study, it is worth to evaluate the possibility of using different sensors on the parameters, especially parameters $B L I, M L I$, and $L L I$.

2. Proposed recommendation for improving the usefulness of deflection bowl parameters. The conditions of the pavement structure encountered today can be different than the conditions used to develop the parameters. Therefore, a practical recommendation was proposed to simplify using the parameters in practice.

\section{Results and analysis}

It is important to mention that sensor offsets used in this study were not exactly identical with those used in the parameters. They are $0,305,610,914$ and $1524 \mathrm{~mm}(0,12,24,36$, and $60 \mathrm{in}$.) from the load, as used for measurement by the FWD device (see equations (1) (3) for comparison).
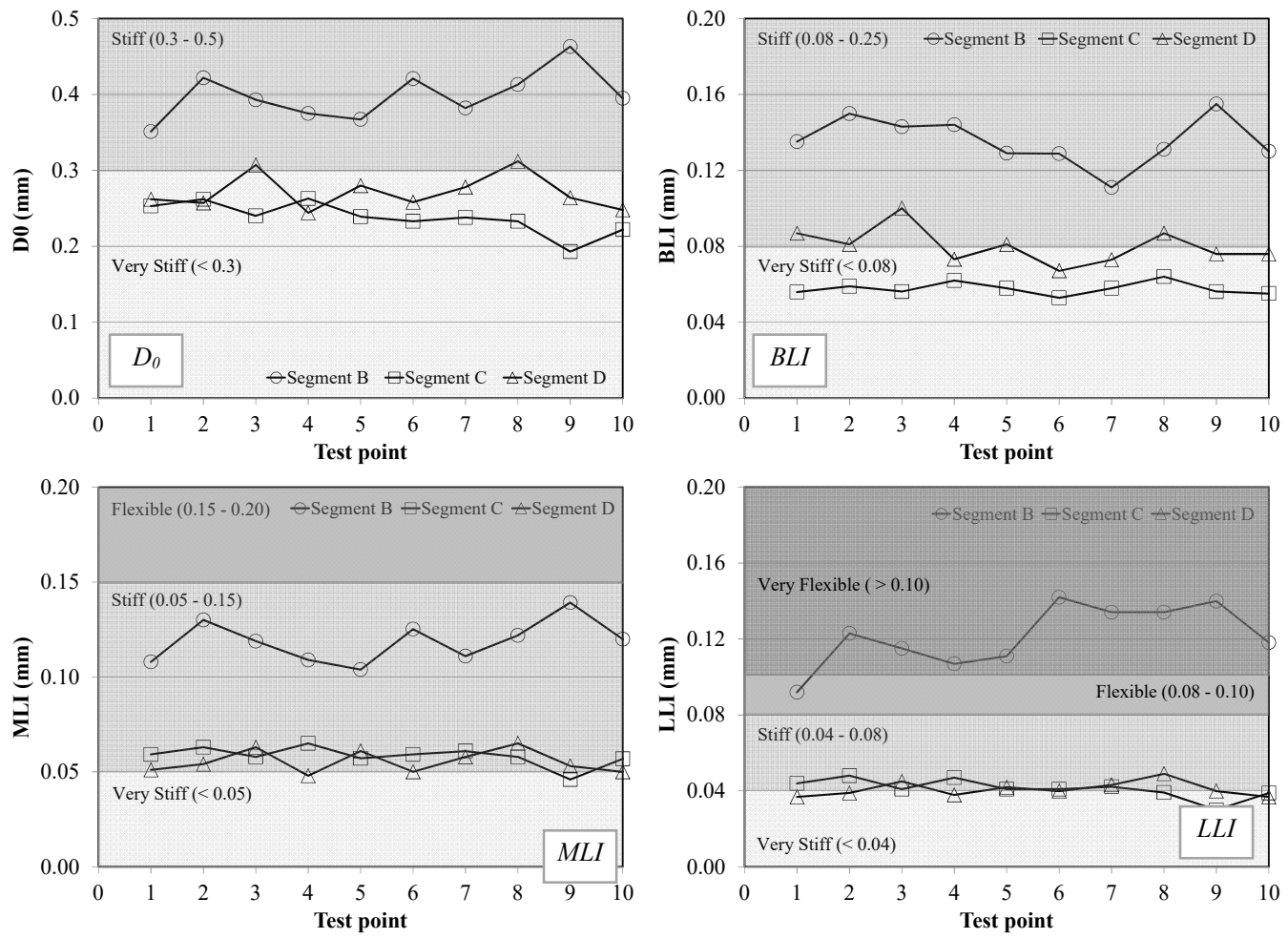

Fig. 1. Behavior states of road segments with different structures 
The deviation of the offset could produce high inaccuracies in back-calculated moduli [5], although this may not be too crucial for determining the indication of the layer condition using deflection bowl parameters.

As stated in the previous section, two evaluations were conducted in this study: (i) the use of non-four-layer pavement structures; and (ii) the use of different sensors on the parameters to do so, evaluation was performed by checking the behavior state of the segments and structural condition rating criteria. Figure 1 shows the assessment of the material behavior states on ten test points of segments with a granular base (i.e., segments $\mathrm{B}, \mathrm{C}$, and D) to see the response of the material under load.

The use of behavior states criteria (Table 1) is very useful to indicate the structural conditions of the layers in terms of elastic response. However, a strict range of behavior states could complicate the evaluation of the structural condition. This can be seen in Fig.1 in which none of the road segments have shown consistency in terms of behavior state. This is because pavement responses are sometimes very unpredictable, depending on many factors such as material homogeneity, layer thickness, the presence of moisture, and so on.

Figures 2 and 3 illustrate an evaluation of the indication of different pavement structures (granular-base and asphaltic-treated-base pavement structures, respectively) by checking their structural conditions and categorizing them into three criteria: sound, warning and severe (see Table 2 for the criteria). Six test points for each segment A, D, E, and F were selected for this evaluation.
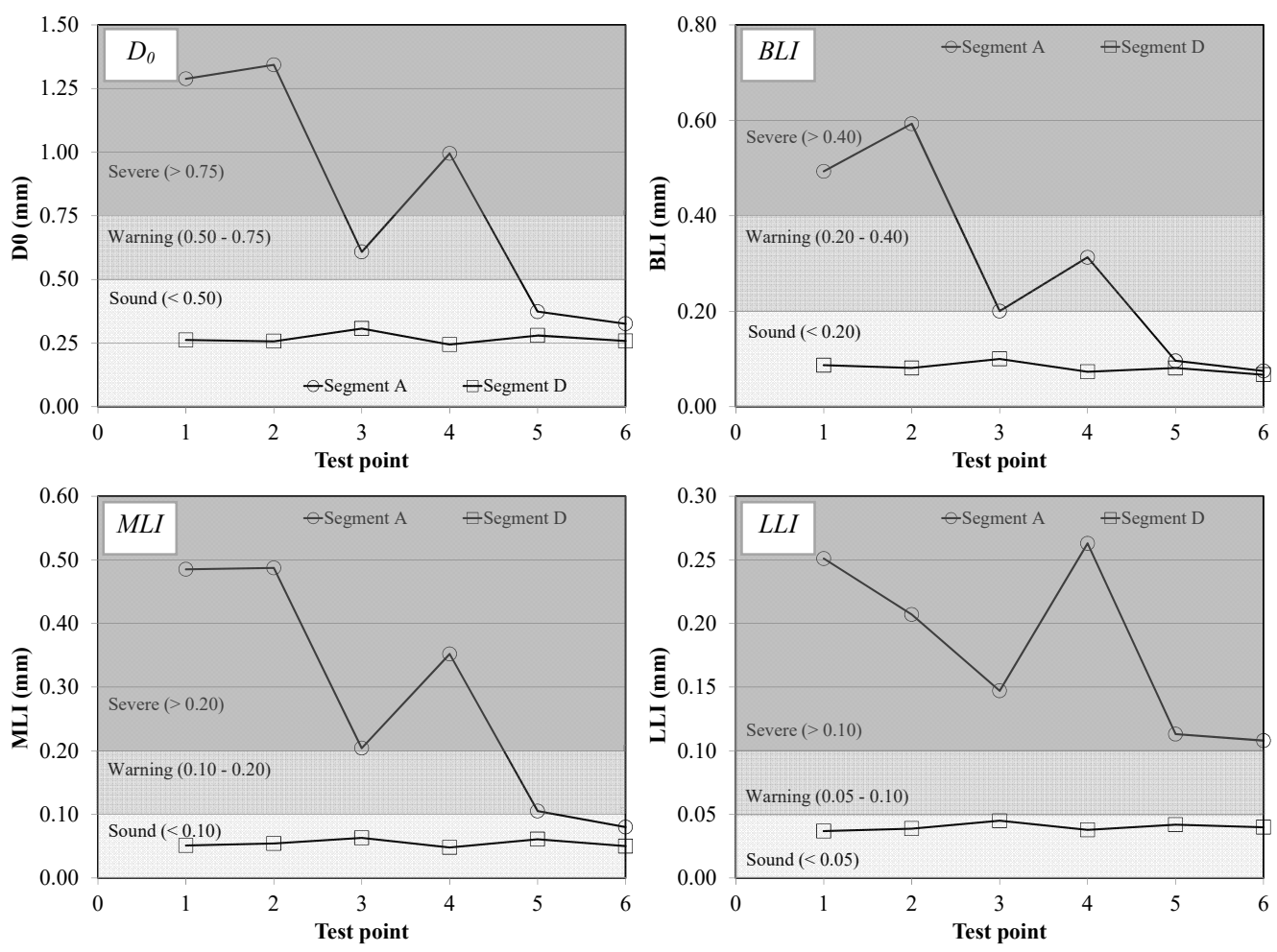

Fig. 2. Evaluation of structural condition of a granular-base pavement structure

It can be seen in Fig. 2 that there are interesting indications found for segments A and $\mathrm{D}$. As seen in the figure, segment $\mathrm{D}$ has a good condition indicated by a sound criterion for all parameters. On the other hand, segment A has a different condition among the test points in the segment. It seems that three parameters $\left(D_{0}, B L I, M L I\right)$ have a similar trend, 
although parameter $L L I$ may lead to confusion and misinterpretation in this case due to the pavement structures not having a subbase layer (see Table 3).

In Fig. 3, both road segments show a similar trend for three parameters $\left(D_{0}, B L I, L L I\right)$. The warning condition for the subbase layer (or MLI parameter) along segment E also raised a question as the subgrade condition of this segment was in sound criterion. This might be caused by the imprecise selection of sensors for the MLI parameter or the improper determination of the rating criteria for the MLI parameter.
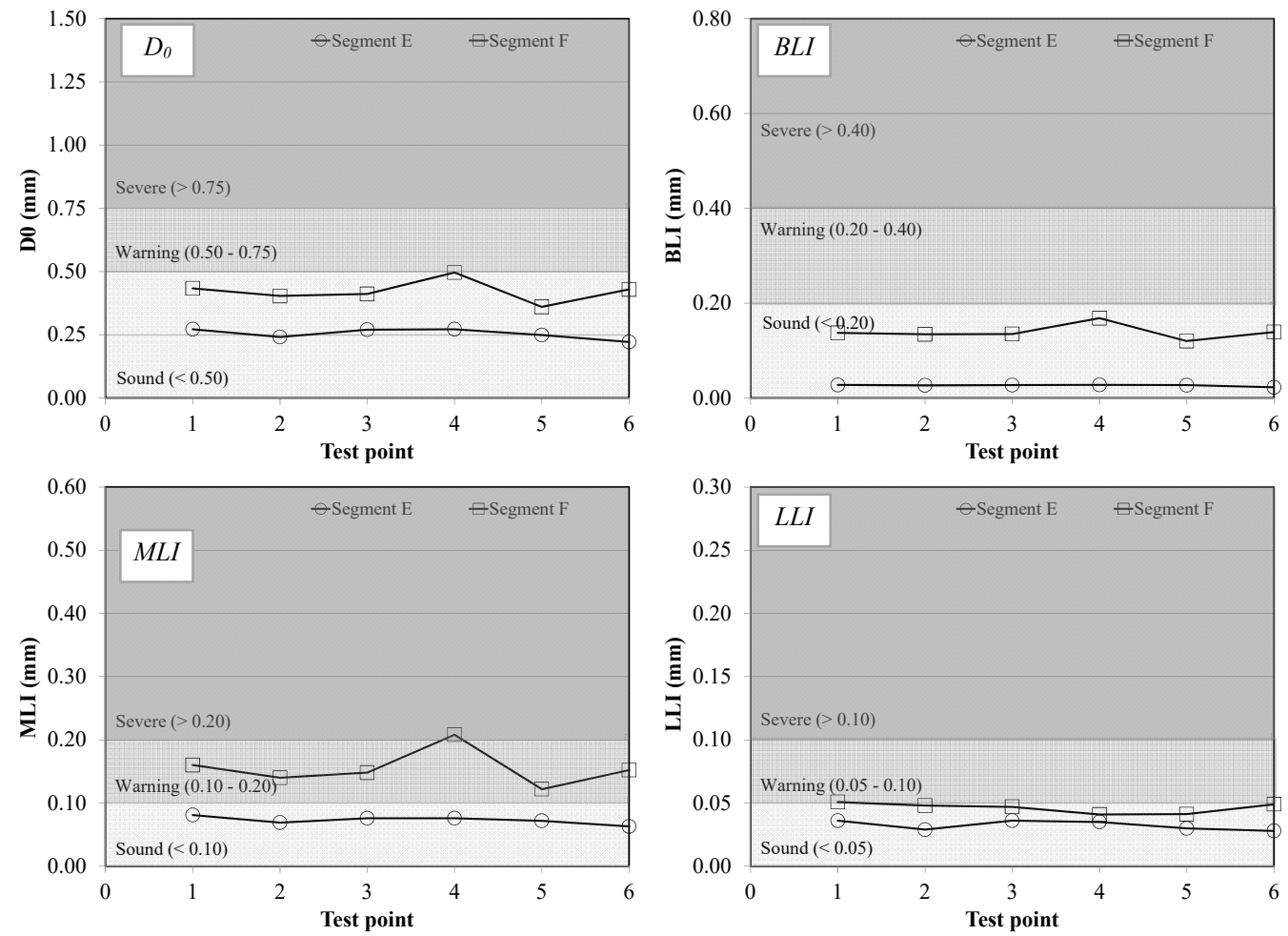

Fig. 3. Evaluation of structural condition of an asphalt-treated-base pavement structure

It is recommended to simplify the deflection bowl parameters into only 3 parameters, i.e., $D_{0}, M L I$, and $L L I$ which represent three parts of pavement structures (surface, base/subbase, and subgrade). The first and last parts are the most important ones to indicate that the pavement layers have a sufficient capability to reduce susceptibility to cracking and rutting, respectively. While the middle part is important for the following: (i) to indicate the condition of middle layers in providing support to the surface layer, and (ii) to show whether the middle layer is affected in case of damage to the surface layer or subgrade.

Another evaluation conducted in this study was the evaluation of different sensor usage on the parameters. It this important to know that to calculate subgrade resilient modulus $\left(M_{r}\right)$, it is required to determine the minimum placement of the outer sensor offset $r$. For this purpose, one could make use of AASHTO equations (4) - (7) $[6,7]$ based on the illustration of stress distribution in Fig. 4. 


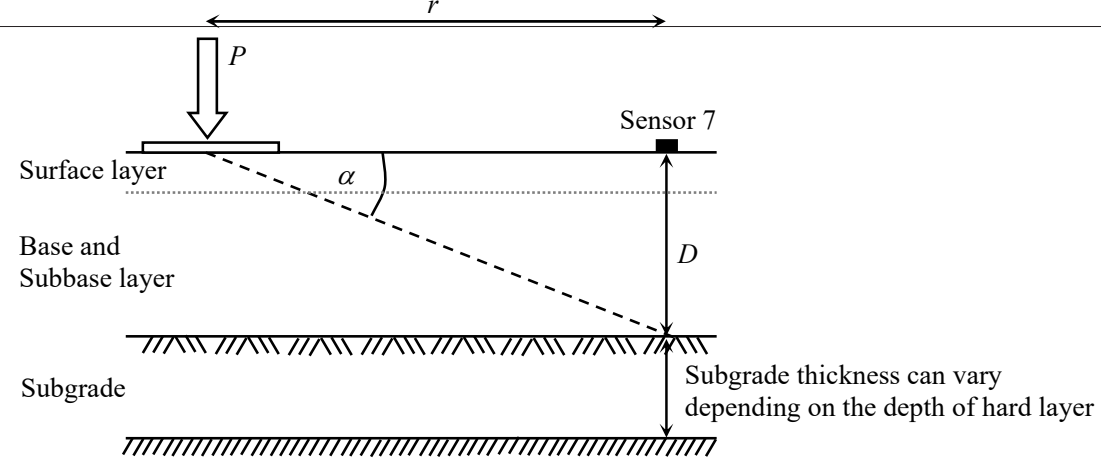

Hard layer

Fig. 4. Typical stress distribution under load drop $[6,7]$

$$
M_{r}=\frac{0,24 P}{d_{r} r}
$$

$M_{r}$ will be considered valid if the following inequality is met.

$$
r>0,7 a_{e}
$$

The offset $0.7 a_{e}$ and composite moduli $E_{p}$ can be determined using the equations below.

$$
\begin{gathered}
a_{e}=\sqrt{a^{2}+\left(D\left(\frac{E_{p}}{M_{r}}\right)^{1 / 3}\right)^{2}} \\
d 0=1,5 p a\left|\frac{\left.1-\frac{1}{M_{r} \sqrt{1+\left(\frac{D_{3}}{a} \sqrt{\frac{E_{p}}{M_{r}}}\right)}}+\frac{\left(\frac{D}{a}\right)^{2}}{E_{p}}\right)}{E_{p}}\right|
\end{gathered}
$$

Using equations (4) - (7), the minimum outer sensor offset required for determining the subgrade modulus can be simulated (see Table 4). This offset is very important to know since the deflection produced by the sensor beyond the minimum offset is the one that accurately represents the response provided by the subgrade [1].

Table 4. Relationship of outer sensor offset to pavement thickness

\begin{tabular}{|c|c|c|}
\hline Road segment & Pavement thickness *) & $\begin{array}{c}\text { Min. outer sensor offset } \\
\text { for subgrade } \\
\text { measurement **) }\end{array}$ \\
\hline A & $7.5 \mathrm{in.}$ & $18 \mathrm{in.}$ \\
\hline $\mathrm{B}$ & $11.9 \mathrm{in}$. & $18 \mathrm{in}$. \\
\hline $\mathrm{C}$ & $24.3 \mathrm{in.}$ & $36 \mathrm{in.}$ \\
\hline $\mathrm{D}$ & $31.5 \mathrm{in}$. & $60 \mathrm{in.}$ \\
\hline $\mathrm{E}$ & $16 \mathrm{in.}$ & $24 \mathrm{in.}$ \\
\hline $\mathrm{F}$ & $28.3 \mathrm{in}$. & $36 \mathrm{in.}$ \\
\hline
\end{tabular}

Remarks: *) thickness without subgrade

**) according to equations (4) - (7) 
As seen in Table 4, the minimum location of the outer sensor subgrade measurement is dependent on the layer thickness. For road segments with two layers above the subgrade, the minimum sensor offset is less than the required offset by the $L L I$ parameter. But this is not the case for segments with many layers or segments with thick layers. For example, segments $\mathrm{C}, \mathrm{D}$, and $\mathrm{F}$ require that the minimum sensor offset for subgrade measurement is 36 in. Whereas the $L L I$ parameter requires that the measurement of the subgrade response is by involving sensor no. 5 and 6 (at distances of 24 and 36 in., respectively). Based on the results in Table 4, it can be recommended that the sensors for the $L L I$ parameter should be the ones that represent the outermost sensor, i.e., sensors with a distance of 914 and 1524 $\mathrm{mm}$ (36 and $60 \mathrm{in}$.) from the load, or in terms of the $L L I$ parameter: $L L I=D_{914}-D_{1524}$.

While the middle layer $(M L I)$ parameter can be represented by the following equation:

$$
M L I=D_{305}-D_{457}
$$

The reason of the use of these sensors is that they are located at a considerable distance from the load center $P$; also, both sensors still can cover the response of the base or subbase layer of a three-layer pavement structure.

\section{Conclusions}

This paper presented an evaluation of existing deflection bowl parameters on several pavement structures in practice. It resulted in: (i) the sensor offsets used in the parameters should be in accordance with those used by the falling-weight deflectometer (FWD) device; (ii) a simplification of the parameters to only 3 parameters $\left(D_{0}, M L I, L L I\right)$ was proposed for the sake of ease in practice; and (iii) reformulation of MLI and LLI were required by taking into account the accuracy of the subgrade modulus determination and the possibility to evaluate pavement structures with a layer number less than four.

\section{References}

1. E. Horak, Benchmarking the structural condition of flexible pavements with deflection bowl parameters, J. of the South African Inst. of Civil Eng. 50, 2 (2008)

2. E. Horak, S. Emery, Falling weight deflectometer bowl parameters as analysis tool for pavement structural evaluations, Proceedings of $22^{\text {nd }}$ ARRB Conference, Canberra (2006)

3. Committee of State Road Authorities (CSRA), Flexible pavement rehabilitation investigation and design, Draft Technical Recommendation for Highways 12 (TRH 12) (Department of Transport, Pretoria, 1997)

4. Federal Highway Administration (FHWA), Long-term pavement performance (LTPP) database, "LTPP Infopave", http://infopave.fhwa.dot.gov, accessed on 25 March 2018

5. R.N. Stubstad, L.H. Irwin, E.O. Lukanen, M.L. Clevenson, it's 10 O'clock - Do you know where your sensors are?, Transp. Res. Rec. 1716 (2000)

6. B.H. Nam, S.H. Kee, H. Youn, D.Y. Kim, Methodology to improve the AASHTO subgrade resilient modulus equation for network-level use, J. Transp. Eng. 141, 12 (2015)

7. AASHTO, AASHTO Guide for Design of Pavement Structures (AASHTO, Washington, DC, 1993) 